\title{
Antibacterial composite cellulose fibers modified with silver nanoparticles and nanosilica
}

\author{
E. Smiechowicz $\cdot$ B. Niekraszewicz $\cdot$ P. Kulpinski $\cdot$ K. Dzitko
}

Received: 21 August 2017/Accepted: 17 April 2018/Published online: 21 April 2018

(C) The Author(s) 2018

\begin{abstract}
In the present research, nanocomposite antibacterial cellulose fibers of Lyocell type modified with nanosilver particles and nanosilica were obtained. Nanosilver particles were generated by the chemical reduction of silver nitrate $\left(\mathrm{AgNO}_{3}\right)$ in $50 \%$ water solution of $\mathrm{N}$-methylmorpholine $\mathrm{N}$-oxide (NMMO), which was applied as a direct cellulose solvent for the production of Lyocell fibers. The main aim of this study has been to obtain antibacterial cellulose fibers modified with silver nanoparticles, which are entirely safe for contact with human tissue. Taking into account the potential medical applications of the obtained fibers, the antibacterial activity and cytotoxicity of silver nanoparticles enclosed in fibers were examined in human and mouse cells. Considering the size of the silver nanoparticles with nanosilica in NMMO and their physical properties, the time of generation was the subject of a thorough analysis. The basic physical properties of the nanoparticles introduced in the fibers were tested using the UV/VIS, DLS and TEM methods. The basic properties of the fibers,
\end{abstract}

E. Smiechowicz $(\bowtie) \cdot$ B. Niekraszewicz · P. Kulpinski Department of Man-Made Fibers, Lodz University of Technology, ul. Zeromskiego 116, 90-924 Lodz, Poland e-mail: emilia.smiechowicz@p.lodz.pl

K. Dzitko

Department of Immunoparasitology, Institute of Microbiology, Biotechnology and Immunology, Faculty of Biology and Environmental Protection, University of Lodz, ul. Banacha 12/16, 90-236 Lodz, Poland namely the mechanical and hydrophilic ones, and the average degree of polymerisation of the cellulose fibers were estimated. The conditions of the synthesis of nanoparticles in NMMO with nanosilica were optimised. The results have confirmed that fibers with high-quality antibacterial properties, safe for human tissue and suitable for medical purposes, could be obtained.

Keywords Cellulose fibers $\cdot$ Lyocell $\cdot$ Silver nanoparticles $\cdot$ Nanosilica

\section{Introduction}

New, functional textile products are in demand in the modern market. At present, silver nanoparticle modification of various products, e.g. plastics, textiles, cosmetics etc., seems to be one of the most popular research topics (Srinivas 2016; Carbone et al. 2016; Gokarneshan and Velumani 2017). Silver nanoparticles are used especially for medical applications, e.g. wound dressings, catheters, aprons, face masks, gloves etc. (Zhang et al. 2016). The unique bioactive properties of medical textiles and the enormous number of potential applications encourages many scientists, research teams and centres around the world to focus their work on a more effective and safe manner of production of textiles modified with silver nanoparticles. Introducing the modifier into the 
polymer matrix is an interesting physical method of modification. One of the most suitable methods for modified fiber production is Lyocell technology, based on NMMO as a direct solvent. According to many scientific papers and patents, cellulose fibers obtained through the NMMO method can be relatively easily modified with various types of inorganic and polymeric modifiers introduced into the cellulose matrix (Kulpinski et al. 2005; Kulpinski 2007a; Kozlowski et al. 2009). Some studies were carried out with nanosilica as a modifier and Ludox SM30 was one of them (Kulpinski et al. 2005). It was shown that it is possible to introduce 30\% Ludox SM30 into the spinning solution and to obtain fibers, but it was observed that over $5 \%$ of this modifier significantly decreases tenacity at break. Conversely, the fibrillation ability of the modified fibers was substantially limited. Based on recent research, NMMO technology also seems to be a very useful method for modifying cellulose fibers with silver nanoparticles, especially since it enables the generation of silver nanoparticles practically at any stage of the process (Laszkiewicz et al. 2006; Smiechowicz et al. 2011).

Wendler et al. obtained Alceru cellulose fibers with silver nanoparticles by introducing colloidal nanosilver (NanoSilver) into the fiber structure. The results showed high antibacterial activity, good tenacity and a high level of whiteness of the produced fibers. The authors, however, underline that it was necessary to apply special stabilisers when nanosilver in its colloidal form was used during the process of dissolving cellulose in NMMO (Wendler et al. 2007).

Zimmer AG mass-produces SeaCell cellulose fibers with algae and SeeCell Active fibers with silver ions besides algae, by introducing the modifier to the polymer matrix of the fibers. Studies proved the antibacterial and antifungal activities of these fibers, but this effect was achieved in an additional stage by applying after-treatment with silver nitrate $\left(\mathrm{AgNO}_{3}\right)$ (Zikeli 2002).

Nanosilica is more often used in composite materials, particularly in medicine. For example, Madhumati et al. (2009) obtained novel chitin/nanosilica composite scaffolds. The incorporation of silica into the chitin scaffold can thus produce a bioactive scaffold, which can be used for tissue engineering applications. It was shown that the addition of silica can improve the bioactivity and biocompatibility of chitin. Quanguo et al. (2012) prepared and characterised silver-loaded antibacterial nanosilica particles. By using the nano/micro silica prepared as a carrier, silver-loaded antibacterial nanosilica particles forming $\mathrm{SiO}_{2} / \mathrm{Ag}$ composites were obtained through silver salt adsorption and subsequent chemical reduction. In this case, such silver-loaded antibacterial silica nanoparticles show an attractive prospect in inorganic oxides utilisation and extended antibacterial application.

Sujoy et al. (2013) obtained a nanosilica-AgNPS composite material as an antifouling nanomaterial for sustainable water purification. Silver nanoparticles of about $10 \mathrm{~nm}$ were synthesised on the surface of nanosilica through protein-mediated reduction of bound silver ions on nanoporous silica. NanosilicaAgNPs showed a long-term antibacterial activity against both planktonic cells and biofilms of Gramnegative Escherichia Coli and Pseudomonas Aerugionosa.

Niekraszewicz (Niekraszewicz 2006) obtained antibacterial cellulose fibers by introducing an inorganic antibacterial agent AlphaSan (silver-zirconium phosphate) into spinning solutions during the dissolution of cellulose in NMMO. An additional introduction of Ludox SM30 nanosilica resulted in the improvement of the antibacterial properties of the fibers. Both the bacteriostatic and bactericidal activities of the fibers were increased. It seems that this was the effect of the good action of nanosilica. Nanosilica creates stronger bonds with silver which consequently leads to slower silver release from the fibers. As a result, it was possible to use less inorganic antibacterial agents, which was important from an economical point of view, as antibacterial silver agents are more expensive than nanomodifiers, especially nanosilica Ludox SM30. Additionally, the lesser amount of antibacterial agents caused the elimination of the disadvantageous colour of the fibers, as opposed to when only antibacterial agent was used. Our latest research (Smiechowicz et al. 2014) has shown the effect of silver nanoparticles' shape, size and distribution on the colour of cellulose fibers.

In this paper, one of the applied methods presents the use of nanosilica as an additional modifier added to the $\mathrm{NMMO}$ and $\mathrm{AgNO}_{3}$ solution during the spinning dope preparation.

For this reason, the main aims of the present research were to obtain new bioactive cellulose fibers modified with silver nanoparticles and nanosilica 
enclosed in the polymer matrix, and study their properties. The frame of the present research involves the estimation of the properties of silver nanoparticles built in the fiber matrix (DLS, TEM, EDX). Also, the antibacterial activity, cytotoxity, and mechanical and hygroscopic properties of modified fibers were determined.

\section{Experimental section}

\section{Materials}

Cellulose pulp (Rayonier Ltd.) containing 98 wt (\%) of $\alpha$-cellulose with an average polymerisation degree of about 1250 (DP) and NMMO as 50\% aqueous solution (from Huntsman Holland BV, the Netherlands) were used in the preparation of the spinning dope. The process of cellulose dissolution was carried out in an IKAVISC kneader. In order to remove the excess water, low pressure $(200 \mathrm{hPa})$ and elevated temperature (up to $115^{\circ} \mathrm{C}$ ) were applied. The propyl ester of gallic acid (Tenox $\mathrm{PG}^{\circledR}$ ) from Aldrich (Gillingham, Dorset, UK) was applied as an antioxidant. Silver nitrate $\left(\mathrm{AgNO}_{3}\right)$ manufactured by the CHEMPUR, Poland was used for the generation of metallic silver nanoparticles. Nanosilica was manufactured by Aldrich, Poland under the trade name Ludox ${ }^{\circledR}$ SM30.

\section{Preparation of the fibers}

In order to obtain cellulose fibers, which contain only silver nanoparticles or silver nanoparticles with nanosilica, the following procedure was carried out:

$0.01 \mathrm{M} \mathrm{AgNO}_{3}$ in aqueous solution was added to a $50 \%$ aqueous NMMO solution. The used amount of $\mathrm{AgNO}_{3}$ corresponded to the theoretically calculated number of silver nanoparticles in the fibers, which equals to $0.05 \%$ (500 ppm). Based on the results from our previous research, the applied concentration of silver nanoparticles enclosed in the polymer matrix of fibers provides good antibacterial properties against Escherichia coli and Staphylococcus aureus (Kulpinski 2007b). The obtained $\mathrm{NMMO}-\mathrm{AgNO}_{3}$ systems were incubated in the darkroom, at the same temperature of $20^{\circ} \mathrm{C}$, but for different amounts of time for each of the prepared samples $(12,24$ and $48 \mathrm{~h}$ respectively).
The AgNps generation process, which took place in the presence of nanosilica, was carried out for the chosen time of the $\mathrm{AgNO}_{3}$ reduction, namely $24 \mathrm{~h}$. The applied time of AgNPs synthesis appeared to be optimal in terms of the even distribution of nanoparticles in the polymer matrix of fibers, as well as the very good antibacterial properties of the modified fibers. A colloidal solution of nanosilica (5 wt\% calculated on the $\alpha$-cellulose contents) was added to the incubated $\mathrm{NMMO}-\mathrm{AgNO}_{3}$ solutions (during the stage of AgNPs synthesis).

After the applied times of AgNPs synthesis, 8\% solution of cellulose in NMMO was prepared using each of the pre-incubated solutions with AgNPs or AgNPs/nanosilica (after the appropriate time of synthesis). The dissolution process was carried out in the kneader, until a homogenous spinning dope was obtained. Fibers were spun using the dry-wet method on a laboratory spinning machine, which has been described in previous works (Smiechowicz et al. 2011).

Table 1 shows the abbreviations for the samples used in the present research.

Instrumentation and methodology

The size and volume distribution of silver nanoparticles were determined by the Dynamic Light Scattering technique (DLS) with a PSS Nicomp 380 particle sizer (Santa Barbara, California) system. The DLS analysis of the size of silver nanoparticles was conducted based on Nikomp Distribution (intensity weighting, volume weighting and number weighting). Nikomp Distribution was generated by PS Nikomp software's CW 388 application (v. 1.55), normalised to $100 \%$.

An independent check of the results obtained by DLS was conducted by transmission electron microscopy (TEM) TECNAI SuperTWIN FEG (200 kV). Shape and size distribution were assessed by the NISElements software.

The energy-dispersive EDX (EDAX Phoenix with a ( $\mathrm{Si} ; \mathrm{Li}$ ) drifted detector with a UTW window sensitive to all elements down to Boron) nanoanalysis was performed to execute elemental analysis and chemical characterisation of selected samples, as well as to confirm the qualitative analysis of silver particles.

Fiber linear density was determined according to ISO 1973:1995 (E). Conditioned tenacity and elongation at break were measured according to $\mathrm{PN}-85 / \mathrm{P}-$ 
Table 1 List of abbreviations

\begin{tabular}{|c|c|c|}
\hline & Sample codes & Mode of preparations \\
\hline SOLUTIONS & $\begin{array}{l}\text { NMMO } \\
\text { NMMO-Ag/12 } \\
\text { NMMO-Ag + Si/24 }\end{array}$ & $\begin{array}{l}50 \% \text { of water solution of NMMO without modifier } \\
\text { solution of NMMO with silver nanoparticles, which were generated over } 12 \mathrm{~h} \\
\text { solution of NMMO with silver nanoparticles, which were generated over } 24 \mathrm{~h} \text { in the } \\
\text { presence of nanosilica }\end{array}$ \\
\hline FIBERS & $\begin{array}{l}\mathrm{F}_{0} \\
\mathrm{~F}_{\mathrm{si}} \\
\mathrm{F}-\mathrm{Ag} / 12 \\
\mathrm{~F}-\mathrm{Ag}+\mathrm{Si} / 24\end{array}$ & $\begin{array}{l}\text { standard cellulose fibers without modifier (unmodified fiber) } \\
\text { cellulose fibers modified with nanosilica without silver nanoparticles } \\
\text { cellulose fibers modified with silver nanoparticles, which were generated over } 12 \mathrm{~h} \\
\text { cellulose fibers modified with silver nanoparticles, which were generated in NMMO } \\
\text { in the presence of nanosilica over } 24 \mathrm{~h}\end{array}$ \\
\hline
\end{tabular}

The second number marked as 12 will be changed into 24 or 48 , depending on the time needed for the process of silver nanoparticles synthesis

04761/04. Measurements were performed using the ZWICK/Z 2.5/TN1S (Ulm, Germany) tensile testing machine with TestXpert v. 7.1 software.

Moisture absorption of the obtained fibers at $65 \%$ at $20{ }^{\circ} \mathrm{C}$ was determined according to Polish standard $\mathrm{PN}-71 / \mathrm{P}-04635$. Water retention was measured in accordance with PN-72/P-04800.

The Japanese Industrial Standard (JIS L 1902: 1998 'Testing method for antibacterial of textiles') was used for the evaluation of the antibacterial efficiency of modified fibers. The test was performed using the Gram-negative strain of Escherichia coli (ATCC 11229) and the Gram-positive strain of Staphylococcus aureus (ATCC 6538). The tests for E. coli (Gramnegative bacteria) and $S$. aureus (Gram-positive bacteria) were carried out. For each sample of cellulose fibres, the bacteriostatic (S) and bactericidal (L) values were calculated. The $\mathrm{S}$ value was expressed by:

$S=\log \frac{M_{b}}{M_{c}}$

where $\mathrm{Mb}$ is the amount of bacteria after $24 \mathrm{~h}$ inoculation of the sample fibres without a modifier, and $\mathrm{Mc}$ is the amount of bacteria after $24 \mathrm{~h}$ inoculation of the sample with a certain amount of modifier.

The $\mathrm{L}$ value was calculated according to the formula:

$L=\frac{M_{a}}{M_{c}}$ where $\mathrm{M}_{\mathrm{a}}$ is the amount of bacteria recovered from the inoculated sample fibres without modifier at the beginning of contact time.

\section{Cytotoxic activity of modified fiber extracts}

- obtaining extracts from modified fibers

In order to obtain extraction fluids from cellulose fibers modified with silver nanoparticles generated from $\mathrm{NMMO}^{-\mathrm{AgNO}_{3}}(\mathrm{~F}-\mathrm{Ag} / 24)$, silver nanoparticles generated from NMMO-AgNO 3 plus nanosilica (F$\mathrm{A}+\mathrm{Si} / 24)$ and non-modified control fibers $\left(\mathrm{F}_{0}\right)$, $0.02 \mathrm{~g}$ of each product was subjected to extraction in strictly defined conditions ( 24 and $48 \mathrm{~h}, 36{ }^{\circ} \mathrm{C}$, rocking incubator) into $1 \mathrm{ml}$ of Dulbecco's Phosphate Buffered Saline (PBS, Sigma) and $1 \mathrm{ml}$ of Iscove's Modified Dulbecco's Medium (IMDM, CytoGen) cultivation medium or $1 \mathrm{ml}$ of PBS and $1 \mathrm{ml}$ of IMDM supplemented with 10\% Fetal Calf Serum (FCS). Extraction fluids were then collected and filtered through $0.2 \mu \mathrm{m}$ bacteriological filters.

- determination of the cytotoxic activity of modified fiber extracts-MTT assay

The determination of the effect of FAg/24 and $\mathrm{F}-\mathrm{Ag}+\mathrm{Si} / 24$ extracts, and non-modified control fibers $\mathrm{F}(0)$ on $\mathrm{L} 929$ cell viability (mice fibroblasts, ATTC-Catalog No. CCL-1TM) was performed using an MTT assay according to the European Standard ISO 10993-5:2009(E), 'Biological evaluation of medical devices, Part 5: Tests for in vitro cytotoxicity’. In 
addition, epithelial-like human cells (HeLa, ATTCCatalog No. CCL-2TM) were used to evaluate cell viability. Cell cultures grown in IMDM and PBS or IMDM and PBS enriched in fetal calf serum (IMDM “+” and PBS “+”) without extract were used as controls.

Cell viability was calculated according to the formula:

$$
\begin{aligned}
\text { Viability }[\%]= & \frac{\text { Absorbance of the tested sample }}{\text { Absorbance of control sample }} \\
& \times 100
\end{aligned}
$$

According to the standard used, a compound was considered as non-toxic to cells unless it reduced cell viability below $70 \%$.

\section{Results and discussion}

Estimation of basic parameters of silver nanoparticles using the DLS and TEM methods

In order to estimate the size, shape and distribution of silver nanoparticles, the dynamic light scattering (DLS) and transmission electron microscopy methods were used. The DLS analysis included the measurement of the size of silver nanoparticles and their agglomerates. Their number and volume weighting were measured according to the method described in detail in previous research (Smiechowicz et al. 2011). According to this method, the measurement of the parameters of silver nanoparticles was carried out only in the solutions. For this reason, the particles were released from the polymer matrix by fibers dissolution but in this state they had a higher tendency to create agglomerates, which strongly scatters the light. The TEM analysis of silver nanoparticles is most convenient for estimating the basic parameters of nanoparticles enclosed in fibers. According to this method, the real state of embedded silver nanoparticles in the fibers was estimated. The additional advantage of TEM analysis is the possibility to observe the particles, as well as to estimate their shape and distribution directly in the polymer matrix of the fibers.

DLS allows for the determination of the diameters of particles in liquid samples only; therefore, it was necessary to dissolve the fibers in order to free the particles from the polymer matrix. All solutions used in the present work were obtained by dissolving fibers containing nanoparticles, so cellulose is one of the main components of the examined solutions. As a consequence, the appropriate concentration of the analysed solutions (the applied amount of fibers was about $0.07 \mathrm{~g}$ ) and the polymerisation degree of cellulose (DP) are two of the most important parameters. Fibers were dissolved in an iron (III) sodium

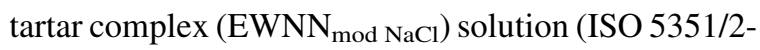
1982) and placed in a laboratory shaker for $1 \mathrm{~h}$. The size of silver nanoparticles in the tested solution was measured at a temperature of $25{ }^{\circ} \mathrm{C}$.

The obtained results are shown in Table 2 and in Fig. 1. Figure 1 shows Nikomp's distribution of silver particles' size generated in an NMMO solution at $20{ }^{\circ} \mathrm{C}$ over $12 \mathrm{~h}$.

According to the DLS theory, the results are divided into three fractions depending on the size of particles in dispersion. The intensity of light dispersion is a parameter which has significant influence on the division of particles. According to the DLS measurement, light dispersion occurs only on the nanoparticles and agglomerates, because in each of the analysed systems obtained by cellulose fibers' dissolution, the fraction from the cellulose macromolecules was not observed. The intensity of light dispersion for the dissolved fibers not containing silver nanoparticles is much lower than for the samples of solution obtained from fibers containing nanoparticles. Based on the above observations, it can be stated that the first fraction represents silver nanoparticles and the second fraction represents silver nanoparticles or agglomerates, depending on the intensity of light dispersion. The third fraction represents only nanoparticles agglomerates. In some cases, the concentration of nanoparticles is below $0.1 \%$, which was marked in Table 1 as $<0.1 \%$. Such results are obtained because of the insufficient resolution of the apparatus or because there was too low a concentration of silver nanoparticles in the sample of cellulose fibers.

Having analysed the results of the dispersion of silver nanoparticles in NMMO, it was concluded that the synthesis of silver nanoparticles at a temperature of $20{ }^{\circ} \mathrm{C}$ at various times allows the generation of nanoparticles of c. 2-40 nm, as presented in Table 1 . It was observed that the size of silver nanoparticles in the fibers modified with them increased dramatically. The diameter of the silver nanoparticles undergoes a 
Table 2 Results of the DLS analysis of the solutions of dissolved fibers in $\mathrm{EWNN}_{\mathrm{mod} \mathrm{NaCl}}$ compared with unmodified cellulose fibers $\mathrm{F}_{0}$, as well as the solutions applied to obtain the presented fibers

\begin{tabular}{|c|c|c|c|c|c|c|c|}
\hline \multirow[t]{2}{*}{ Sample } & \multirow{2}{*}{$\begin{array}{l}\text { Fraction } \\
\text { no. }\end{array}$} & \multicolumn{2}{|c|}{ Volume weighting } & \multicolumn{2}{|c|}{ Number weighting } & \multicolumn{2}{|c|}{ Intensity weighting } \\
\hline & & $\begin{array}{l}\text { Diameter } \\
(\mathrm{nm})\end{array}$ & $\begin{array}{l}\text { Percentage } \\
(\%)\end{array}$ & $\begin{array}{l}\text { Diameter } \\
(\mathrm{nm})\end{array}$ & $\begin{array}{l}\text { Percentage } \\
(\%)\end{array}$ & $\begin{array}{l}\text { Diameter } \\
(\mathrm{nm})\end{array}$ & $\begin{array}{l}\text { Percentage } \\
(\%)\end{array}$ \\
\hline $\mathrm{F}_{0}$ & 1 & 3.8 & 100 & 3.8 & 100 & 4.3 & 100 \\
\hline NMMO & 1 & 423.7 & 100 & 410.5 & 100 & 408.4 & 100 \\
\hline \multirow{3}{*}{$\begin{array}{l}\text { NMMO-Ag/ } \\
12\end{array}$} & 1 & 2.3 & 98.4 & 2.2 & 100 & 2.4 & 15.0 \\
\hline & 2 & 15.2 & 1.6 & 14.5 & $<0.1$ & 17.5 & 85.0 \\
\hline & 3 & - & - & - & - & - & - \\
\hline \multirow[t]{3}{*}{$\mathrm{F}-\mathrm{Ag} / 12$} & 1 & 20.3 & 89.2 & 19.8 & 98.7 & 22.4 & 4.0 \\
\hline & 2 & 99.0 & 5.2 & 94.1 & 1.2 & 108.3 & 27.1 \\
\hline & 3 & 799.8 & 5.5 & 742.7 & 0.1 & 742.7 & 68.9 \\
\hline \multirow{3}{*}{$\begin{array}{l}\text { NMMO-Ag/ } \\
24\end{array}$} & 1 & 2.5 & 97.4 & 2.5 & 99.9 & 2.3 & 0.6 \\
\hline & 2 & 44.2 & 2.6 & 42.0 & 0.1 & 48.7 & 99.4 \\
\hline & 3 & - & - & - & - & - & - \\
\hline \multirow[t]{3}{*}{$\mathrm{F}-\mathrm{Ag} / 24$} & 1 & 22.6 & 61.1 & 21.5 & 99.0 & 24.3 & 4.9 \\
\hline & 2 & 209.5 & 1.2 & 202.6 & 0.2 & 230.7 & 95.1 \\
\hline & 3 & 1627.5 & 37.7 & 1576.5 & 0.8 & 1576.2 & 86.0 \\
\hline \multirow{3}{*}{$\begin{array}{l}\text { NMMO-Ag/ } \\
\quad 48\end{array}$} & 1 & 3.2 & 97.9 & 3.0 & 99.8 & 3.8 & 4.9 \\
\hline & 2 & 32.4 & 2.1 & 30.7 & 0.2 & 35.8 & 95.1 \\
\hline & 3 & - & - & - & - & - & - \\
\hline \multirow[t]{3}{*}{ F-Ag/48 } & 1 & - & - & - & - & - & - \\
\hline & 2 & 118.3 & 10.7 & 112.0 & 71.6 & 128.7 & 19.2 \\
\hline & 3 & 2422.8 & 89.3 & 2422.8 & 28.4 & 2422.8 & 80.8 \\
\hline
\end{tabular}

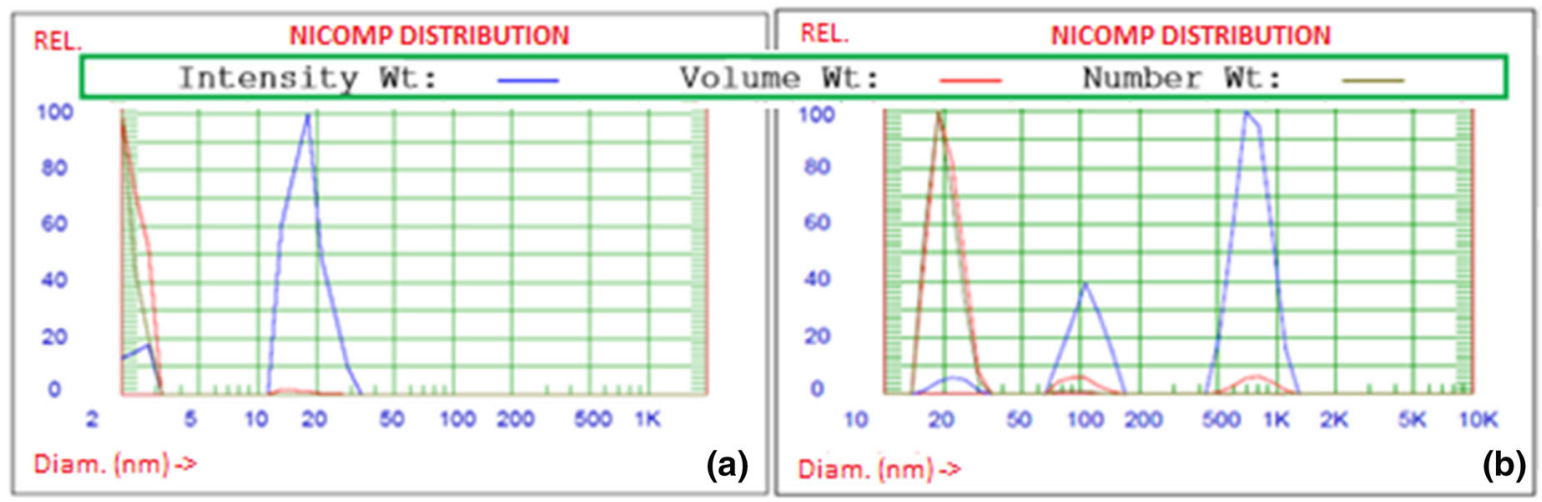

Fig. 1 Distribution of silver particles' size generated in an NMMO solution a NMMO-Ag/12, b nanoparticles from cellulose fibers F-Ag/12

change when the duration of the synthesis is modified. For the shortest synthesis durations in NMMO (12-24 h), silver nanoparticles with a diameter of $\mathrm{c}$. $20 \mathrm{~nm}$ are most likely to be created in the fibers (F-Ag/ 12 and $\mathrm{F}-\mathrm{Ag} / 24)$. In the aforementioned fibers, agglomerates of silver nanoparticles of $70-800 \mathrm{~nm}$ $(\mathrm{F}-\mathrm{Ag} / 12)$ are formed; interestingly, their size is almost twice as big (200-1600 nm) when the synthesis is prolonged to $24 \mathrm{~h}$. Further extension of the synthesis of silver nanoparticles to $48 \mathrm{~h}$ leads to a situation 
where only agglomerates of particles of c. 120-2500 $\mathrm{nm}$ are visible in the fibers (for a dissolved fiber F-Ag/48). The sizes of silver nanoparticles generated in NMMO with nanosilica for the selected times of synthesis are shown in Table 3.

Following the process of dissolving fibers, which "freed" silver nanoparticles, the size of the particles in modified fibers was estimated. Measurements of the size of particles in fibers with nanosilica and without silver nanoparticles, and in aqueous NMMO solutions with dispersed silver nanoparticles and nanosilica were carried out.

Figure 2 presents Nikomp's distribution of silver nanoparticles' size generated in an NMMO with nanosilica at $20^{\circ} \mathrm{C}$ over $24 \mathrm{~h}$. Nanoparticles from cellulose fibers are also shown.

The results of the DLS tests carried out on fibers modified solely with colloidal nanosilica $\left(\mathrm{F}_{\mathrm{si}}\right)$ show that the modifier has a strong tendency to agglomerate due to the fact that the colloidal solution introduced into the cellulose pulp contained nanosilica particles as small as $7 \mathrm{~nm}$. In the obtained cellulose fibers, however, silica nanoparticles formed a high number of larger agglomerates as big as $67 \mathrm{~nm}$ (c. 97\%) and about $3 \%$ of large agglomerates $1759 \mathrm{~nm}$. In this solution, light underwent dispersion mainly in the largest agglomerates $(83 \%)$. The content of nanosilica introduced into the fibers was $5 \% \mathrm{w} / \mathrm{w}$. This means that it was the dominant ingredient in the system, which considerably affected the size of the particles in the solution. In the solution (NMMO-Ag $+\mathrm{Si} / 24$ ), there are silver nanoparticles with a size below $100 \mathrm{~nm}$ but they are not detectable by the DLS method. In this system, the strong signal of the large particles and their aggregates $(110 \mathrm{~nm})$ or agglomerates $(900-4400 \mathrm{~nm})$ dominates the signal coming from small particles. Nevertheless, the presence of small nanoparticles was proved in fibers by the TEM analysis discussed in this paper. Synthesising at $20{ }^{\circ} \mathrm{C}$ for $24 \mathrm{~h}, 20 \%$ of considerably larger agglomerates of about $400 \mathrm{~nm}$ were formed. A reverse result was observed for the fibers obtained with the solutions containing silver nanoparticles. The smaller particles $(14.5 \mathrm{~nm})$, with a bigger share (90-99\%) were formed in the solution of fibers $\mathrm{F}-\mathrm{Ag}+\mathrm{Si} / 24$. In addition, a small fraction of large agglomerates (c. $1750 \mathrm{~nm}$ ) was found in fibers. Comparing the fibers obtained in the same conditions, but without nanosilica (Table 2), it can be observed that introducing nanosilica into the system affected the agglomeration processes of formed nanoparticles as bigger particles and larger agglomerates were formed.

\section{Silver nanoparticles size estimation using the TEM method}

In order to verify the results obtained with the DLS method, the TEM technique was applied. TEM is a useful method which allows for direct observations of extremely small objects. In this case, TEM enables the

Table 3 Results of the DLS analysis of the solutions of dissolved fibers in $\mathrm{EWNN}_{\text {mod } \mathrm{NaCl}}$ compared with unmodified fibers $\mathrm{F}_{0}$ and fibers modified with nanosilica without silver nanoparticles $\mathrm{F}_{\mathrm{si}}$, as well as the solutions applied to obtain the presented fibers

\begin{tabular}{|c|c|c|c|c|c|c|c|}
\hline \multirow[t]{2}{*}{ Sample } & \multirow{2}{*}{$\begin{array}{l}\text { Fraction } \\
\text { no. }\end{array}$} & \multicolumn{2}{|c|}{ Volume weighting } & \multicolumn{2}{|c|}{ Number weighting } & \multicolumn{2}{|c|}{ Intensity weighting } \\
\hline & & $\begin{array}{l}\text { Diameter } \\
(\mathrm{nm})\end{array}$ & $\begin{array}{l}\text { Percentage } \\
(\%)\end{array}$ & $\begin{array}{l}\text { Diameter } \\
(\mathrm{nm})\end{array}$ & $\begin{array}{l}\text { Percentage } \\
(\%)\end{array}$ & $\begin{array}{l}\text { Diameter } \\
(\mathrm{nm})\end{array}$ & $\begin{array}{l}\text { Percentage } \\
(\%)\end{array}$ \\
\hline $\mathrm{F}_{0}$ & 1 & 3.8 & 100.0 & 3.8 & 100.0 & 4.3 & 100.0 \\
\hline \multirow[t]{3}{*}{$\mathrm{F}_{\mathrm{si}}$} & 1 & - & - & - & - & - & - \\
\hline & 2 & 67.3 & 48.4 & 66.9 & 96.7 & 68.5 & 17.0 \\
\hline & 3 & 1759.8 & 51.6 & 1731.7 & 3.3 & 1731.7 & 83.0 \\
\hline \multirow{3}{*}{$\underset{24}{\mathrm{NMMO}-\mathrm{Ag}}+\mathrm{Si} /$} & 1 & 110.0 & 5.8 & 102.7 & 64.7 & 120.3 & 9.8 \\
\hline & 2 & 870.7 & 12.3 & 838.0 & 15.7 & 838.0 & 40.2 \\
\hline & 3 & 4371.0 & 82.0 & 4175.6 & 19.6 & 4175.6 & 50.0 \\
\hline \multirow[t]{3}{*}{$\mathrm{F}-\mathrm{Ag}+\mathrm{Si} / 24$} & 1 & 14.5 & 89.6 & 14.3 & 99.9 & 15.2 & 3.1 \\
\hline & 2 & 531.8 & 1.4 & 514.4 & $<0.1$ & 512.8 & 96.9 \\
\hline & 3 & 1744.3 & 9.0 & 1692.8 & 0.1 & - & - \\
\hline
\end{tabular}




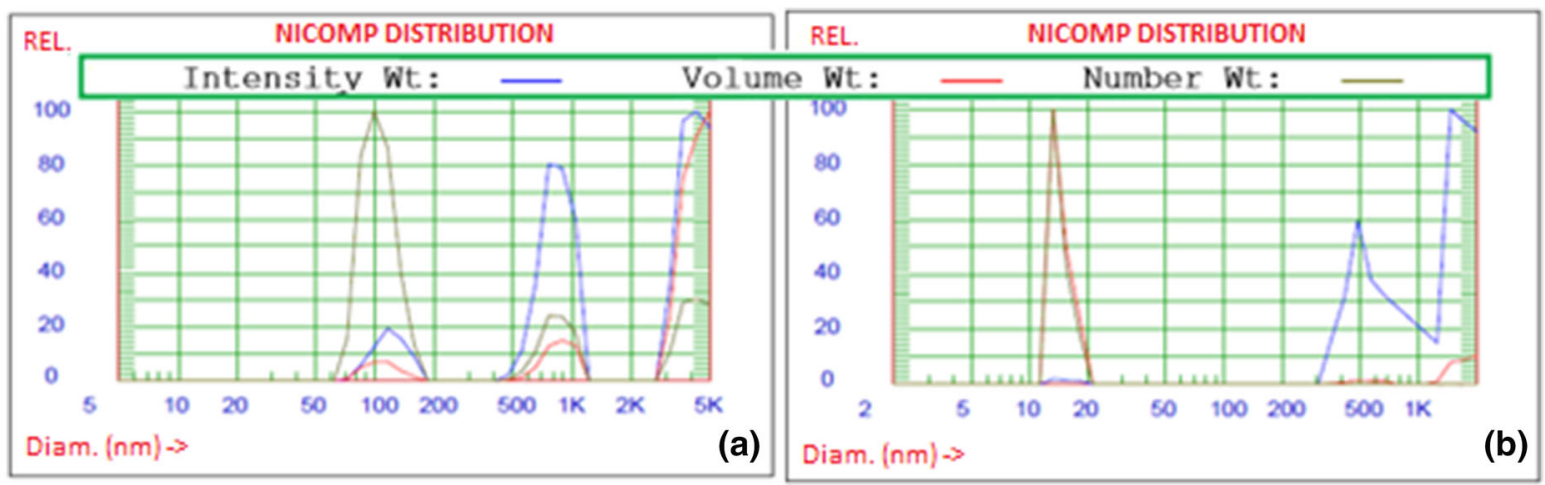

Fig. 2 Distribution of silver particles' size generated in an NMMO solution with nanosilica a NMMO-Ag $+\mathrm{Si} / 24$, b nanoparticles from cellulose fibers $\mathrm{F}-\mathrm{Ag}+\mathrm{Si} / 24$

characterisation of silver nanoparticles enclosed in the polymer matrix of cellulose fibers in a more detailed way. Based on a series of observations using the TEM method performed with the bright field (BF) and high resolution (HR) techniques] it was possible to estimate not only the distribution size but also the shape of silver nanoparticles.

The histogram presenting the range of sizes of the particles was created on the basis of TEM pictures (particles were counted in each of the images). They present the relation between the distribution of particle sizes and their number in the matrix of cellulose fibers. Additionally, the percentage in reference to each of the sizes of silver nanoparticles was given. In some of the fibers modified with silver nanoparticles, aggregates of particles are visible, which significantly influences the numerical contribution of nanoparticles. Therefore, the relation between the range of the sizes of the particles generated in the fibers and their number with the percentage underlining their proportion was presented. For each of the histograms, the average size of the particles, the standard deviation of the particles' diameter (s), and their minimum and maximum diameter $\left(D_{\min }, D_{\max }\right)$ were calculated. In the case of particles that are shaped elliptically defined by their length and width, the following was discovered:

1. Average aspect ratio of elliptical particles:

$$
W=\frac{L_{\max }}{L_{\min }}
$$

where: $\mathrm{L}_{\text {max. }}, \mathrm{L}_{\text {min. }}-$ maximum and minimum length axis of the ellipse.

2. Eccentricity of ellipse e:

$$
e=\sqrt{1-\frac{L_{\min }^{2}}{L_{\max }^{2}}}
$$

The value of eccentricity of an ellipse is less than 1 $(0<\mathrm{e}<1)$.

For all of the above described parameters, standard deviation was calculated, $\mathrm{s}_{\mathrm{w}}$ and $\mathrm{s}_{\mathrm{e}}$ respectively.

TEM analysis of the basic parameters of silver nanoparticles generated at $20{ }^{\circ} \mathrm{C}$ for different durations of synthesis and introduced into the cellulose fibers

\section{- fibers sample F-Ag/12}

TEM images of elliptical silver nanoparticles and their aggregates in cellulose fibers F-Ag/12 are shown in Fig. 3. The size distribution of silver nanoparticles with the average standard deviations of the size of nanoparticles (s) and their basic parameters are shown in Fig. 4.

In the case of silver nanoparticles synthesised in NMMO at $20{ }^{\circ} \mathrm{C}$ for $12 \mathrm{~h}$, their shape is elliptic and the particles obtained in the cellulose matrix are beanshaped (Fig. 3a).

The median elliptic $\overline{\mathrm{W}}$ and eccentricity $\overline{\mathrm{e}}$ factors, which were 1.35 and 0.65 respectively, proved the elliptic shape of the particles. In the analysed fiber F-Ag/12, nanoparticles varying from c. 2.4 to c. $81 \mathrm{~nm}$, and their aggregates of c. 1200, 300 and $400 \mathrm{~nm}$ (Fig. 3c) were observed. The median size D of the particles is $22.7 \mathrm{~nm}$. These results also show that nanoparticles of a size close to the median (from 20 to 

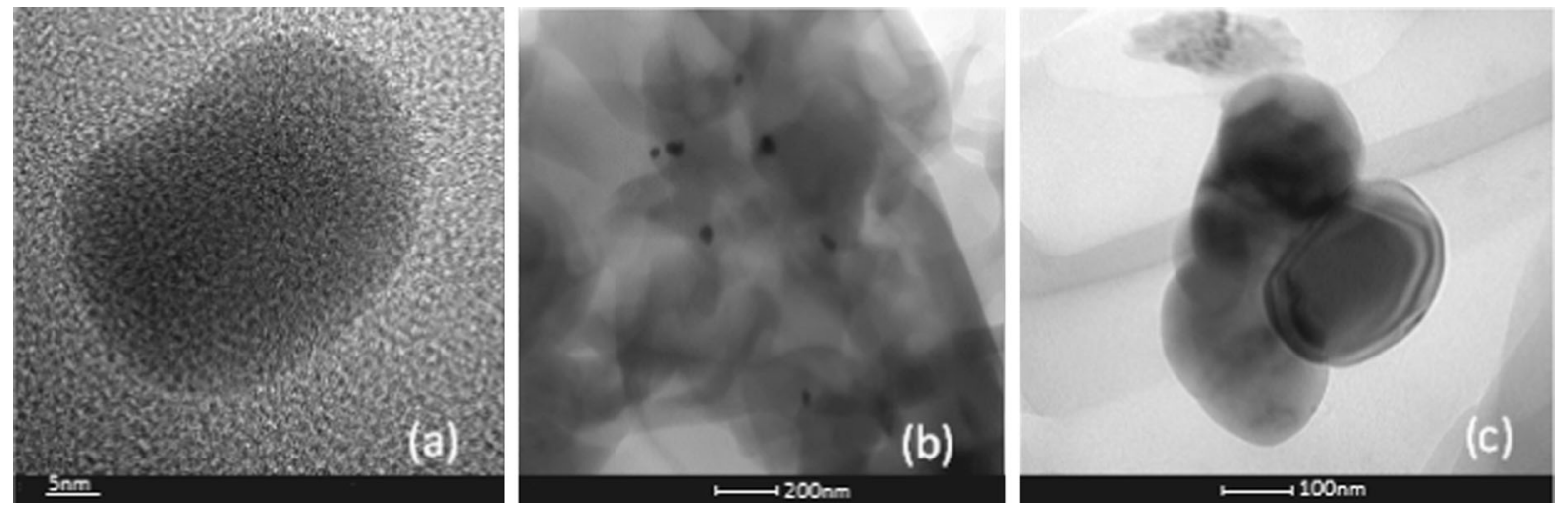

Fig. 3 TEM images of silver nanoparticles enclosed in fibers F-Ag/12: a under high resolution electron microscopy; b, c silver nanoparticles in bright field

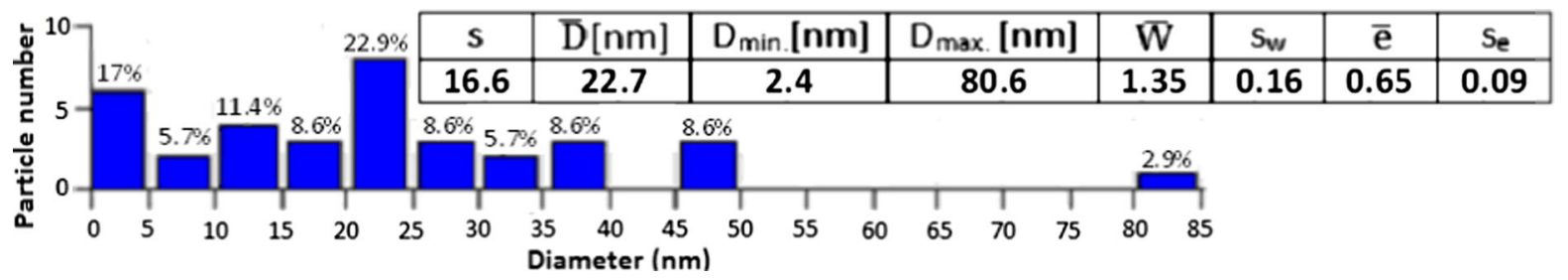

Fig. 4 Silver nanoparticle size distributions in the polymer matrix of fibers F-Ag/12

$25 \mathrm{~nm}$ ) are found in the largest part of the population $(22.9 \%)$. As there is a sizable number of large particles between 15 and $30 \mathrm{~nm}$ in fibers, as well as their aggregates, the distance between the nanoparticles and their uneven distribution in the polymer matrix (Fig. 3b) is clearly visible in TEM images (Fig. 3). The average size of particles, which is $23 \mathrm{~nm}$, and a large number of particles with a diameter as long as 20-25 nm prove that the reduction of silver ions was more effective when the reaction mixture was placed together with cellulose and heated and steered into the laboratory kneader, which stands in contrast to a $12 \mathrm{~h}$ synthesis in NMMO.

\section{- fibers sample F-Ag/24}

TEM images of elliptical and spherical silver nanoparticles in cellulose fibers F-Ag/24 are shown in Fig. 5. The size distribution of silver nanoparticles with the average standard deviations of the size of nanoparticles (s) and their basic parameters are shown in Fig. 6.

Analysing the histogram of sizes of silver nanoparticles in fiber F-Ag/24 (Fig. 6), it can be observed that they ranged between 8 and $60 \mathrm{~nm}$ in size, with the majority of particles between 15 and $30 \mathrm{~nm}$. In the matrix of the analysed fiber, it can be noticed that there is a minor contribution of small silver nanoparticles with a size of just a few nanometers. These could not have been estimated due to the insufficient definition of TEM images. The synthesis of silver nanoparticles in NMMO during $24 \mathrm{~h}$ allowed for the generation of both elliptic (with an elliptic factor of 1.33 and eccentricity of 0.64 ) and spherical particles, as shown in Fig. 5a. What can be observed in the TEM images are only relatively small aggregates of particles c. $150 \mathrm{~nm}$ (Fig. 5c). Image 5b of particles presented in Fig. 5 indicates that particles in fiber $\mathrm{F}-\mathrm{Ag} / 24$ are more evenly distributed than in the fiber modified with silver nanoparticles synthesised for $12 \mathrm{~h}$ at the same temperature of $20^{\circ} \mathrm{C}(\mathrm{F}-\mathrm{Ag} / 12)$.

- fibers sample F-Ag/48

TEM images of spherical silver nanoparticles in cellulose fibers F-Ag/48 are shown in Fig. 7. The size distribution of silver nanoparticles with the average standard deviations of the size of nanoparticles (s) and their basic parameters are shown in Fig. 8. 


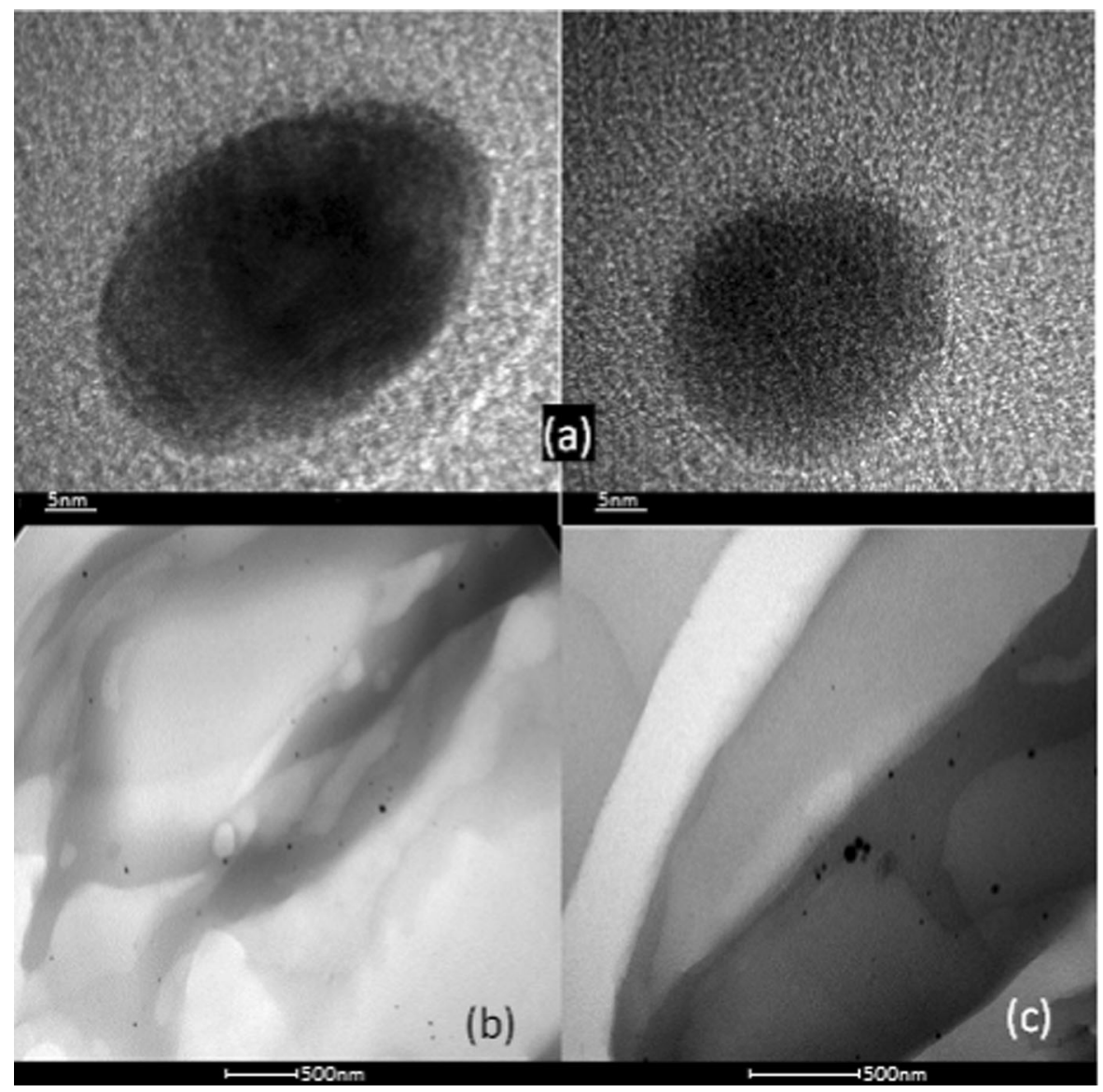

Fig. 5 TEM images of silver nanoparticles enclosed in fibers F-Ag/24: a under high resolution electron microscopy; b, c silver nanoparticles in bright field

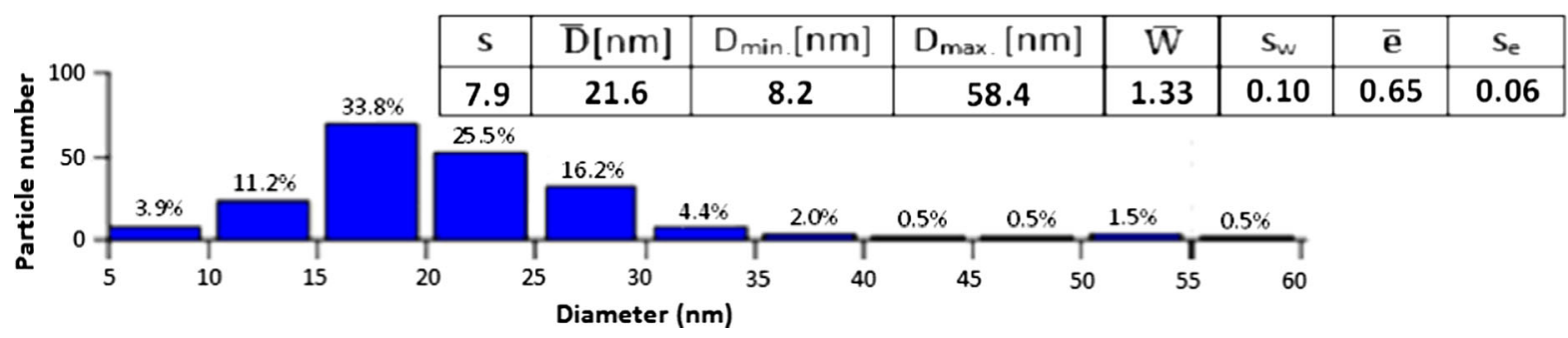

Fig. 6 Silver nanoparticle size distributions in the polymer matrix of fibers F-Ag/24

In fiber F-Ag/48, the size of the obtained silver nanoparticles ranged between 2 and $55 \mathrm{~nm}$, with the majority being shaped spherically. In TEM images, a small number of elliptical particles (with the median shape factor of 1.31 and the median eccentricity of 0.63) can be observed. The majority of particles observed in the analysed fiber have a radiant ranging from 2 to $5 \mathrm{~nm}$ (Fig. 8). TEM images (Fig. 7) show that small nanoparticles are prone to agglomeration (d). Moreover, aggregates of particles as big as 1000 and $1500 \mathrm{~nm}$ can be observed (c). In Fig. 7, in bright field (b), silver nanoparticles are relatively evenly distributed in the polymer matrix of the fiber. Silver nanoparticles synthesised with nanosilica at $20^{\circ} \mathrm{C}$ over $24 \mathrm{~h}$ were analysed by DLS method and introduced into spinning dope. 


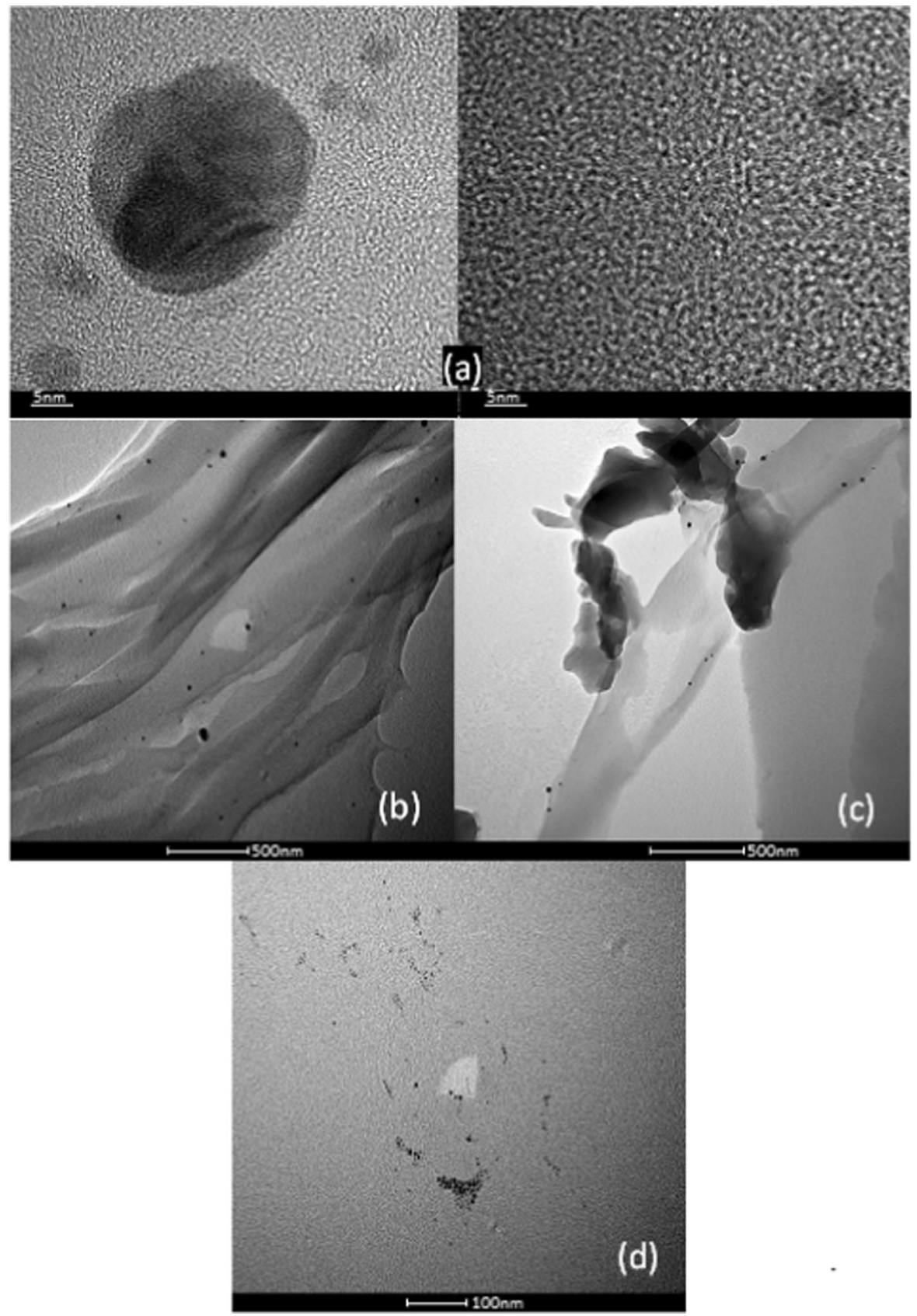

Fig. 7 TEM images of silver nanoparticles enclosed in fibers F-Ag/48: a under high resolution electron microscopy; b-d silver nanoparticles and their aggregates in bright field

- fibers sample F-Ag $+\mathrm{Si} / 24$

Images of nanoparticles and their agglomerates obtained by TEM for fibers $\mathrm{F}-\mathrm{Ag}+\mathrm{Si} / 24$ are shown in Fig. 9.

Images of nanoparticles and their agglomerates obtained by TEM for fibers $\mathrm{F}-\mathrm{Ag}+\mathrm{Si} / 24$ are shown in Fig. 9. Images of silver nanoparticles taken by HREM (Fig. 9a) confirm the presence of both spherical and elliptical particles, which were observed in fiber F-Ag/24 modified with silver nanoparticles obtained under the same conditions as fiber F-Ag + $\mathrm{Si} / 24$ with nanosilica. 


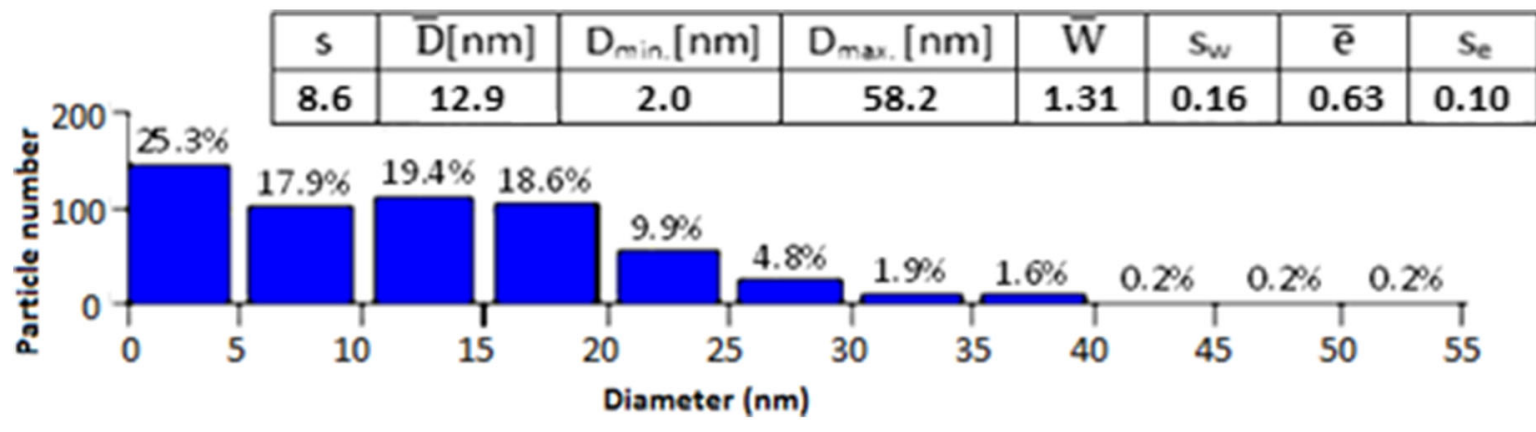

Fig. 8 Silver nanoparticle size distributions in the polymer matrix of fibers F-Ag/48
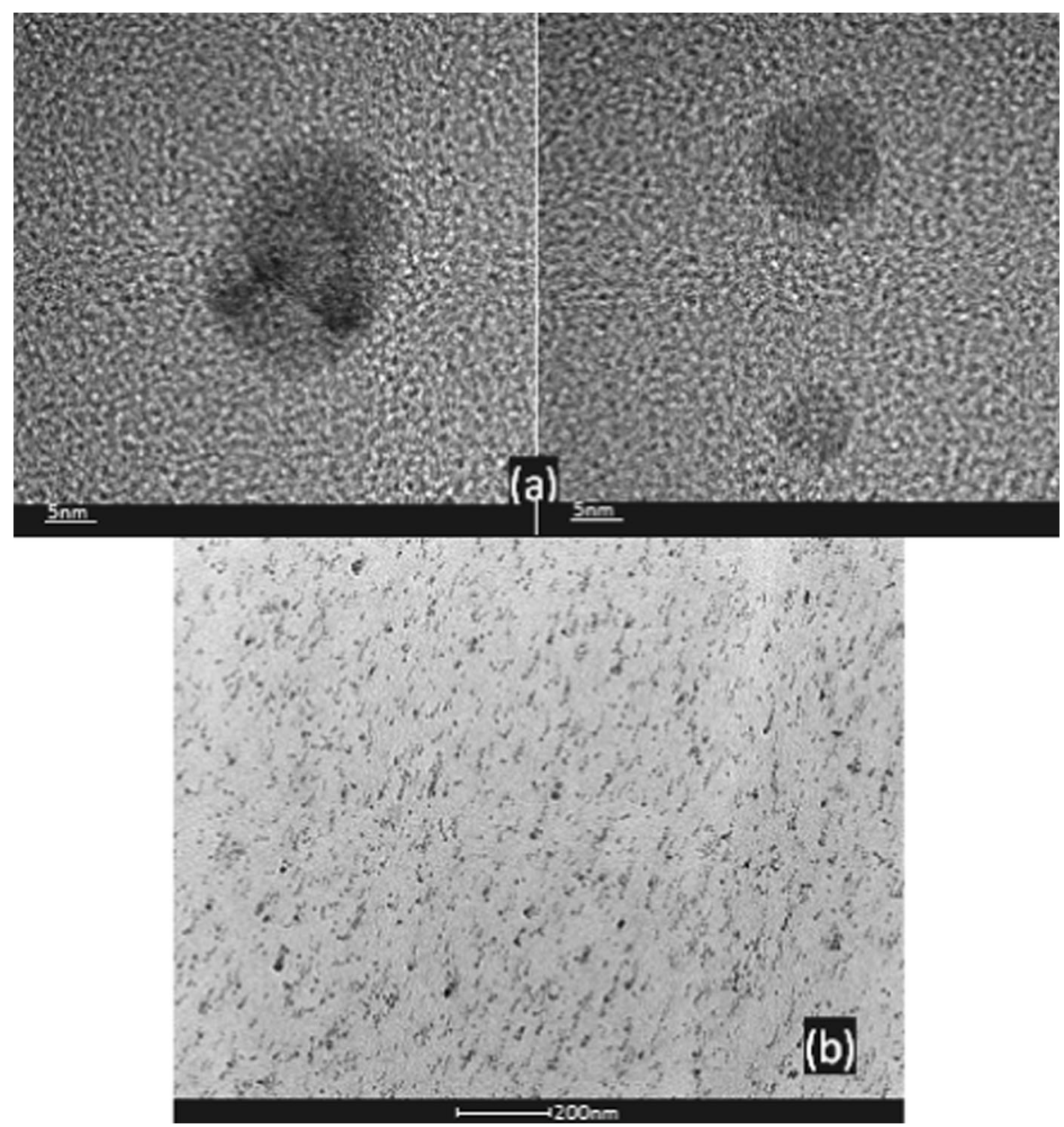

Fig. 9 TEM images of silver nanoparticles enclosed in fibers $\mathrm{F}-\mathrm{Ag}+\mathrm{Si} / 24$ : a high resolution electron microscopy; b silver nanoparticles and nanosilica in bright field

Furthermore, in bright field (Fig. 9b), a high density of nanosilica introduced into the fiber can be noticed, which have an even distribution across the fiber. The size of the silver nanoparticles obtained in the fiber is comparable to the size of those generated in the fiber without nanosilica, which is its base fiber (F-Ag/24). 
Microanalysis of the polymer matrix of fibers using the EDS method

Using Energy Dispersive Spectrometry, major inorganic elements (silver nanoparticles and nanosilica) in the cellulose fibers $(\mathrm{F}-\mathrm{Ag} / 24$ and $\mathrm{F}-\mathrm{Ag}+\mathrm{Si} / 24)$ were identified. Both fibers were obtained by introducing silver nanoparticles synthesised at $20{ }^{\circ} \mathrm{C}$ for $24 \mathrm{~h}$. The results are shown in Figs. 10 and 11. Figure 10 shows a TEM image in the dark field of silver nanoparticles synthesised at $20{ }^{\circ} \mathrm{C}$ for $24 \mathrm{~h}(\mathrm{~F}-\mathrm{Ag} / 24)$ (a) and EDS spectrum (b) of the red marked area on (a). Figure 11 shows a TEM image of silver nanoparticles (generated at $20{ }^{\circ} \mathrm{C}$ for $24 \mathrm{~h}$ ) in dark field (F-Ag $+\mathrm{Si} / 24$ ) (a) and chemical composition analysis (b and c) of the red marked areas on (a).

Tests on the chemical composition in certain areas of the selected fibers, which are presented in Fig. 11, proved that the particles marked with red in the TEM pictures are silver nanoparticles. In EDS spectra included in this section and obtained for each of the fibers, peaks which prove the presence of silver nanoparticles can be easily noticed. In EDS spectra for the fiber modified with both silver nanoparticles and nanosilica (F-Ag $+\mathrm{Si} / 24)$, peaks of silica are also observed, which prove its presence in the matrix of the fiber. In the presented EDS spectra, peaks of copper can be noticed due to the fact that during the analysis the fibers were placed on a copper net.

\section{Estimation of the antibacterial activity of the fibers}

The Japanese Industrial Standard JIS L 1902:1998 was used to determine the antibacterial efficiency of the obtained fibers. After incubating for $24 \mathrm{~h}$ at $37^{\circ} \mathrm{C}$, the difference between germ counts (the number of colony-forming units, CFU) on fibers and on the reference sample was determined. According to Zikeli, antibacterial activity can be divided into three groups: slight, significant and strong. Slight activity occurs when the difference of log CFU between the fiber and the reference sample equals 0 . Significant activity occurs when that difference is greater than 1 and strong activity takes place when that difference is greater than 3 (Zikeli 2002). The selected fibers were tested against the Escherichia coli bacterium-a representative of Gram negative bacteria-and Staphylococcus aureus, a representative of Gram positive bacteria. The antibacterial properties of the fibers with silver nanoparticles synthesised from NMMO- $\mathrm{AgNO}_{3}$ in various synthesis conditions were tested. The selected fibers were modified with silver nanoparticles
Fig. 10 a TEM image of silver nanoparticles in fiber $\mathrm{F}-\mathrm{Ag} / 24$ in dark field with marked red area (point 1) and $\mathbf{b}$ EDS spectrum analysis in point 1 . (Color figure online)
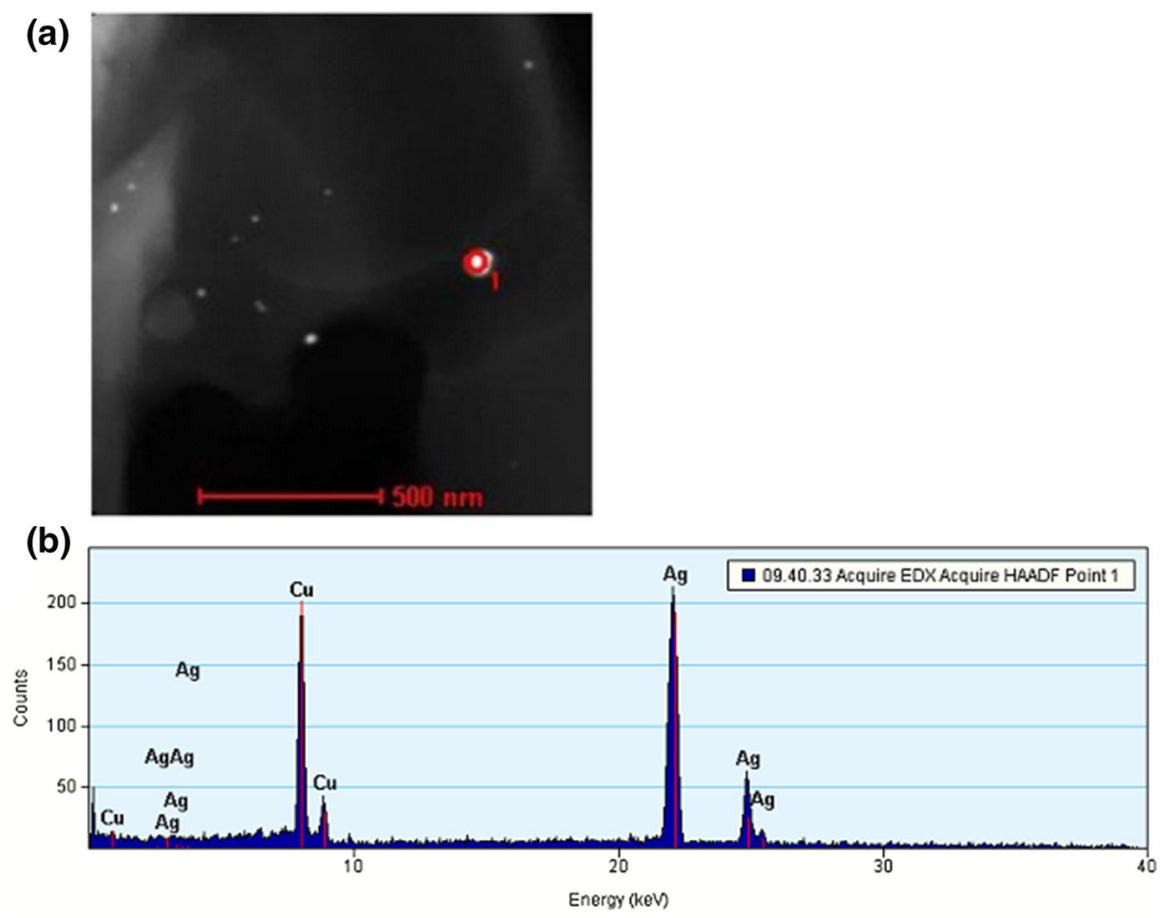
Fig. 11 a TEM image of silver nanoparticles in fiber $\mathrm{F}-\mathrm{Ag}+\mathrm{Si} / 24$ in dark field with marked red area, b EDS spectrum analysis in point 1 and $\mathbf{c}$ EDS spectrum analysis in point 2 . (Color figure online)

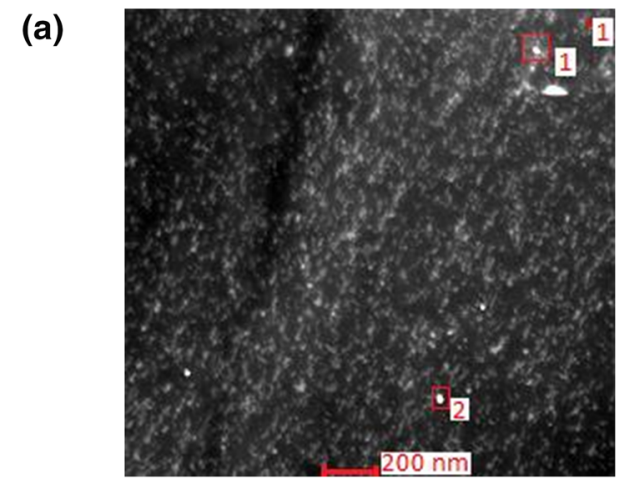

(b)
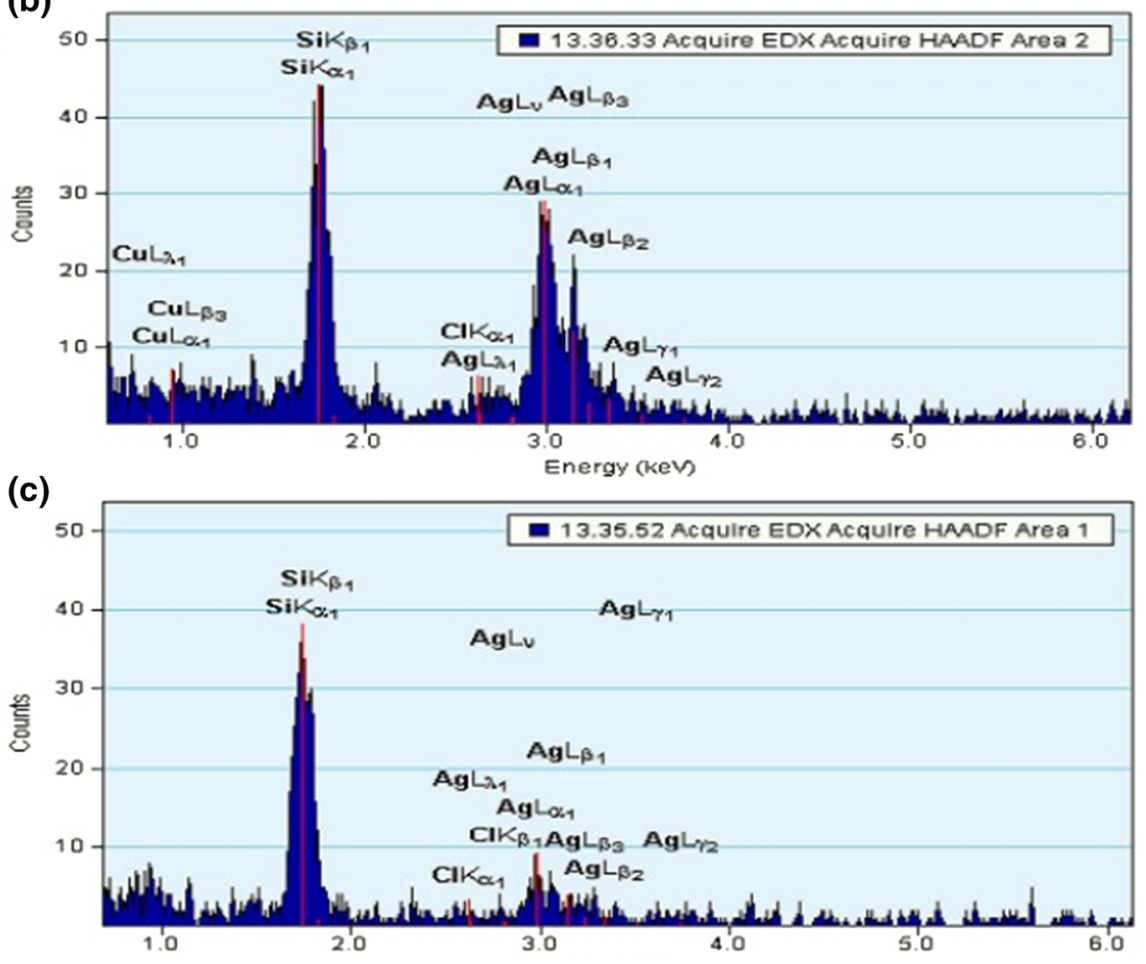

synthesised in the NMMO-AgNO 3 and NMMO$\mathrm{AgNO}_{3}$-LUDOX systems. Antibacterial activity was tested only in the fibers modified with nanoparticles obtained during 12, 24 and $48 \mathrm{~h}$, as well as in the fibers modified with silver nanoparticles and nanosilica during $24 \mathrm{~h}$. The results of the tests on the antibacterial activity of the selected fibers against Escherichia coli and Staphylococcus aureus are shown in Tables 4 and 5.

Having analysed the results of the tests on the selected fibers modified with silver nanoparticles synthesised in NMMO at different times and temperatures, it can be concluded that fiber F-Ag/12 with silver nanoparticles synthesised in NMMO at the lowest of the applied temperatures, namely $20^{\circ} \mathrm{C}$, and for the shortest time- $12 \mathrm{~h}$-displays a very low bacteriostatic and bactericidal activity, or even a lack of activity, which can be explained, according to some researchers (Yu et al. 2003; Gutarowska et al. 2009). Fibers F-Ag/24 and F-Ag/48, modified with silver nanoparticles at $20^{\circ} \mathrm{C}$ and during 24 and $48 \mathrm{~h}$ respectively, display good or very good antibacterial characteristics. In the case of fiber F-Ag/24, its good antibacterial activity stems from the lack of large aggregates, from the large share of nanoparticles between 8 and $30 \mathrm{~nm}$, and from the infinitesimal share 
Table 4 Results of tests on the antibacterial activity of the fibers modified with silver nanoparticles against Escherichia coli

\begin{tabular}{llllll}
\hline Sample & Time (h) & $\begin{array}{l}\text { Number of } \\
\text { bacteria (jtk/pr) }\end{array}$ & $\begin{array}{l}\text { Bacteriostatic } \\
\text { effectiveness (S) }\end{array}$ & $\begin{array}{l}\text { Bactericidal } \\
\text { effectiveness (L) }\end{array}$ & $\begin{array}{l}\text { Antibacterial } \\
\text { activity }\end{array}$ \\
\hline Reference sample & 0 & $2.1 \times 10^{4}$ & - & - & - \\
Reference sample & 24 & $1.4 \times 10^{8}$ & - & - & - \\
F-Ag/12 & 24 & $<20$ & 1.8 & -2.0 & Only bacteriostatic \\
F-Ag/24 & 24 & $<20$ & 6.8 & 3.0 & Strong \\
F-Ag + Si/24 & 24 & $<20$ & 6.9 & 2.7 & Significant \\
F-Ag/48 & 24 & $<20$ & 7.0 & 3.7 & Strong \\
\hline
\end{tabular}

Table 5 Results of tests on the antibacterial activity of the fibers modified with silver nanoparticles and silver nanoparticles with nanosilica against Staphylococcus aureus

\begin{tabular}{llllll}
\hline Sample & $\begin{array}{l}\text { Time } \\
(\mathrm{h})\end{array}$ & $\begin{array}{l}\text { Number of bacteria }(\mathrm{jtk} / \\
\text { pr })\end{array}$ & $\begin{array}{l}\text { Bacteriostatic effectiveness } \\
(\mathrm{S})\end{array}$ & $\begin{array}{l}\text { Bactericidal effectiveness } \\
(\mathrm{L})\end{array}$ & $\begin{array}{l}\text { Antibacterial } \\
\text { activity }\end{array}$ \\
\hline $\begin{array}{c}\text { Reference } \\
\text { sample }\end{array}$ & 0 & $3.7 \times 10^{4}$ & - & - & - \\
$\begin{array}{c}\text { Reference } \\
\text { sample }\end{array}$ & 24 & $7.7 \times 10^{6}$ & - & - & - \\
F-Ag/12 & 24 & $<20$ & & -0.4 & Only \\
& & 1.9 & & $\begin{array}{c}\text { bacteriostatic } \\
\text { Significant }\end{array}$ \\
F-Ag/24 & 24 & $<20$ & 4.6 & 2.3 & $\begin{array}{l}\text { Strong } \\
\text { F-Ag }+ \text { Si } / 24\end{array}$ \\
F-Ag/48 & 24 & $<20$ & 5.3 & 3.5 & Significant \\
\hline
\end{tabular}

of very small particles of just a few nanometers (TEM analysis, Figs. 5, 6). In contrast, in fiber F-Ag/48, a number of aggregates, as well as a large share of very small silver nanoparticles between 2 and $5 \mathrm{~nm}$, can be observed (TEM analysis, Figs. 7, 8), the presence of which is the reason for the satisfactory antibacterial properties of the fibers. The comparison of fiber F-Ag/ 24 and fibers $\mathrm{F}-\mathrm{Ag}+\mathrm{Si} / 24$ shows that the latter displays increased antibacterial activity against $S$. aureus and decreased activity against E. coli from strong to significant. This results directly from the introduction of nanosilica into fiber F-Ag $+\mathrm{Si} / 24$.

Evaluation of the effect of extracts obtained from modified fibers on the viability of human and mouse cells

The influence of 24 and $48 \mathrm{~h}$ extracts obtained from $\mathrm{F}-\mathrm{Ag} / 24$ and $\mathrm{F}-\mathrm{Ag}+\mathrm{Si} / 24$ modified cellulose fibers on the viability of the two cell lines: mouse L929 and human HeLa, was tested and compared with the effect of control fibers $\left(\mathrm{F}_{0}\right)$.

The results obtained in the experiment are presented in Table 6 and Table 7.

Silver nanoparticles and nanosilica-modified fiber extracts $(\mathrm{F}-\mathrm{Ag}+\mathrm{Si} / 24)$ did not affect the viability of the examined cells irrespective of extraction time (24 or $48 \mathrm{~h}$ ) and the media in which they were obtained (PBS or IMDM). Metabolic activity at mitochondrial level was comparable to that of the cells cultured in the presence of untreated control fiber extracts. Statistically significant cytotoxicity, albeit very low, at a level close to that considered as non-toxic $(\leq 30 \%)$ was observed in the case of $24 \mathrm{~h}$ (33.36\% of toxicity) and $48 \mathrm{~h}(33.48 \%)$ fiber extracts of F-Ag $+\mathrm{Si} / 24$ obtained only in PBS supplemented with FBS. The decrease in cell viability (45.89 and 58.26\%) was observed irrespective of the cell line used in the presence of PBS F-Ag/24 extracts but only modified with silver nanoparticles. In addition, a further decrease in cell activity was observed to 84.89 and $81.38 \%$ 
Table 6 Evaluation of the cytotoxicity (\%) of $24 \mathrm{~h}$ (A) and $48 \mathrm{~h}$ (B) extracts obtained from F-Ag/24 and F-Ag + Si/24 modified fibers and $\mathrm{F}_{0}$ control fibers in IMDM and PBS or in IMDM and PBS enriched with FCS (IMDM “+" and PBS “+”) on the viability of mouse cells L929

\begin{tabular}{lllll}
\hline Cell lines & Medium & \multicolumn{2}{l}{ Extracts cytotoxicity (\%) } \\
\cline { 3 - 5 } & & F-Ag/24 & F-Ag $+\mathrm{Si} / 24$ & $\mathrm{~F}_{0}$ \\
\hline A (24 h) & & & & \\
L929 & PBS & 45.89 & $\mathrm{nt}$ & $\mathrm{nt}$ \\
& PBS+ & $32.02^{*}$ & $\mathrm{nt}$ & $\mathrm{nt}$ \\
& IMDM & $\mathrm{nt}$ & $\mathrm{nt}$ & $\mathrm{nt}$ \\
& IMDM+ & $\mathrm{nt}$ & $\mathrm{nt}$ & $\mathrm{nt}$ \\
B (48 h) & & & & \\
L929 & PBS & 84.89 & $\mathrm{nt}$ & $\mathrm{nt}$ \\
& PBS + & 36.42 & $\mathrm{nt}$ & $\mathrm{nt}$ \\
& IMDM & $\mathrm{nt}$ & $\mathrm{nt}$ & $\mathrm{nt}$ \\
& IMDM + & $\mathrm{nt}$ & $\mathrm{nt}$ & $\mathrm{nt}$ \\
\hline
\end{tabular}

$* p<0.05$; nt, non cytotoxic; L929, mouse fibroblasts, ATTCCatalog No. CCL-1TM, PBS, Dulbecco's phosphate buffered saline, IMDM, Iscove's modified Dulbecco's medium; +, PBS or medium supplemented with $10 \%$ fetal calf serum

Table 7 Evaluation of the cytotoxicity (\%) of $24 \mathrm{~h} \mathrm{(A)} \mathrm{and}$ $48 \mathrm{~h}$ (B) extracts obtained from F-Ag/24 and F-Ag $+\mathrm{Si} / 24$ modified fibers and $F_{0}$ control fibers in IMDM and PBS or in IMDM and PBS enriched with FCS (IMDM “+” and PBS “+”) on the viability of human cells HeLa

\begin{tabular}{lllll}
\hline Cell lines & Medium & \multicolumn{3}{l}{ Extracts cytotoxicity (\%) } \\
\cline { 5 - 5 } & & F-Ag/24 & F-Ag $+\mathrm{Si} / 24$ & $\mathrm{~F}_{0}$ \\
\hline A (24 h) & & & & \\
HeLa & PBS & 58.26 & $\mathrm{nt}$ & $\mathrm{nt}$ \\
& PBS+ & $\mathrm{nt}$ & $33.36^{*}$ & $\mathrm{nt}$ \\
& IMDM & $\mathrm{nt}$ & $\mathrm{nt}$ & $\mathrm{nt}$ \\
& IMDM+ & $\mathrm{nt}$ & $\mathrm{nt}$ & $\mathrm{nt}$ \\
B (48 h) & & & & \\
HeLa & PBS & 81.38 & $\mathrm{nt}$ & $\mathrm{nt}$ \\
& PBS + & 44.17 & $33.48^{*}$ & $\mathrm{nt}$ \\
& IMDM & $\mathrm{nt}$ & $\mathrm{nt}$ & $\mathrm{nt}$ \\
& IMDM + & $\mathrm{nt}$ & $\mathrm{nt}$ & $\mathrm{nt}$ \\
\hline
\end{tabular}

${ }^{*} p<0.05$; nt, non cytotoxic; HeLa, epithelial-like human cells; PBS, Dulbecco's phosphate buffered saline, IMDM, Iscove's modified Dulbecco's medium; + , PBS or medium supplemented with $10 \%$ fetal calf serum

respectively for both L929 and HeLa cell lines incubated in the presence of $48 \mathrm{~h} \mathrm{~F}-\mathrm{Ag} / 24$ fiber extracts. A decrease of the cytotoxic activity of these extracts to $36.42 \%$ (L929) and $44.17 \%$ (HeLa) was demonstrated following the addition of fetal calf serum to PBS. Both 24 and $48 \mathrm{~h}$ extracts of F-Ag/24 fibers obtained in IMDM + and in pure IMDM medium (IMDM-) had no cytotoxic effects on human (HeLa) and mouse (L929) cell lines.

The cytotoxicity results of extracts of fibers modified with silver nanoparticles and nanosilica have confirmed the hypothesis that applying silica nanoparticles as an additional modifier in a considerably larger share than the share of silver nanoparticles impedes the release of silver nanoparticles.

According to scientific papers, there are some alternative methods for the estimation of the cytotoxicity of nanoparticles. It seems to be very important to compare the toxicity data obtained via different methods in order to explain cell response to nanoparticles exposure (Fede et al. 2012). There are many studies, however, concerning the toxicity of silver and silica nanoparticles, but the precise mechanism of interaction between living cells and silica nanoparticles, and the silver-silica nanoparticles system are still not known, requiring further investigations (Kim et al. 2015; Fede et al. 2012; Rabolli et al. 2011; Besinis et al. 2014; Schneider 2017).

Determining the mechanical properties of cellulose fibers

This research aimed at assessing the influence of silver nanoparticles introduced into the fibers on average parameters defining the mechanical properties of the fibers, namely their linear density, conditioned tenacity and elongation at break. Tests were carried out on all fibers modified with silver nanoparticles, as well as on selected fiber with both silver nanoparticles and nanosilica. The reference cellulose fiber without the modifier was also tested. The results are shown in Table 8.

Differences between fibers with and without the modifier $\mathrm{F}_{0}$, both in conditioned tenacity (at about a few cN/tex) and in elongation at break (Table 8) may stem from the character of cellulose, which as a natural polymer is heterogeneous, and from the process of spinning. On the basis of these tests, it can be concluded that introducing silver nanoparticles into fibers does not influence their mechanical properties. Comparing the results of conditioned tenacity on fiber $\mathrm{F}-\mathrm{Ag}+\mathrm{Si} / 24$ and $\mathrm{F}-\mathrm{Ag} / 24$ without nanosilica, a 
Table 8 Results of fibers with silver nanoparticles with and without nanosilica synthesised at $20{ }^{\circ} \mathrm{C}$
Table 9 Results of tests on the moisture absorption and water retention of fibers with silver nanoparticles, $\mathrm{F}-\mathrm{Ag}+\mathrm{Si} / 24$ and $\mathrm{F}_{\mathrm{si}}$

\begin{tabular}{llll}
\hline Sample & Linear density $($ dtex $)$ & Conditioned tenacity $(\mathrm{cN} /$ tex $)$ & Elongation at break $(\%)$ \\
\hline $\mathrm{F}_{0}$ & 2.96 & 28.85 & 7.68 \\
$\mathrm{~F}-\mathrm{Ag} / 12$ & 3.16 & 25.14 & 7.49 \\
$\mathrm{~F}-\mathrm{Ag} / 24$ & 3.56 & 24.44 & 6.89 \\
$\mathrm{~F}-\mathrm{Ag} / 48$ & 3.40 & 24.34 & 6.75 \\
$\mathrm{~F}_{\mathrm{si}}$ & 3.26 & 22.62 & 9.68 \\
$\mathrm{~F}-\mathrm{Ag}+\mathrm{Si} / 24$ & 3.20 & 25.28 & 9.52 \\
\hline
\end{tabular}

\begin{tabular}{lll}
\hline Sample & Moisture absorption $(\mathrm{W}, \%)$ & Water retention $(\mathrm{R}, \%)$ \\
\hline $\mathrm{F}_{0}$ & 11.61 & 65.03 \\
$\mathrm{~F}-\mathrm{Ag} / 12$ & 11.10 & 61.65 \\
$\mathrm{~F}-\mathrm{Ag} / 24$ & 10.61 & 63.85 \\
$\mathrm{~F}-\mathrm{Ag} / 48$ & 10.40 & 61.03 \\
$\mathrm{~F}-\mathrm{Si}$ & 12.39 & 68.59 \\
$\mathrm{~F}-\mathrm{Ag}+\mathrm{Si} / 24$ & 12.29 & 62.65 \\
\hline
\end{tabular}

into the fibers. Since their number is very small, it cannot be assumed that the modifier or the modifying conditions influence the hygroscopic parameters of the fibers. When a fiber is modified with nanosilica, the influence on these parameters is observed. Cellulose fibers with nanosilica, as well as those with nanosilica and silver nanoparticles, display an increase in moisture sorption and water retention. The small influence of nanosilica on the hygroscopic parameters of fibers originates from a higher share of nanosilica in comparison to the share of silver nanoparticles in the matrix of the fiber. Nevertheless, the change is slight and, thus, it cannot be argued that modifiers influence the hydrophilic properties of modified cellulose fibers.

\section{Conclusion}

Cellulose fibers modified with silver nanoparticles and silver nanoparticles with nanosilica were obtained. Antibacterial characteristics parallel the basic parameters of silver nanoparticles present in the fibers Compatibility of antibacterial efficacy with the basic parameters of silver nanoparticles present in the fibers is noticeable (in size, shape, ability to form aggregates and their distribution in the polymer matrix). The obtained cellulose fibers revealed good and very good antibacterial characteristics against $E$. coli and $S$. aureus respectively. The presence of silver and silica 
nanoparticles in the polymer matrix was proven with $\mathrm{X}$-ray Microanalysis.

The addition of nanosilica to the fibers however, may contribute to the elimination of the negative effects of silver nanoparticles present in the fiber matrix, as demonstrated by in vitro studies using human and mouse cell lines. The survival of L929 and HeLa cells in the fiber extracts oscillates around 70\%, regardless of the extraction medium used. It can, therefore, be concluded that the extracts of these fibers are not cytotoxic when tested in vitro against chosen cell lines. The addition of nanosilica to the fibers' matrix allows for the elimination of the toxicity of silver nanoparticles on human tissue.

Tests on the mechanical and hygroscopic parameters in fibers with silver nanoparticles compared with fiber without the modifier proved that when the share of silver nanoparticles in the fiber is slight $(0.05 \%)$, the basic parameters are not affected. Nanosilica, as a modifier, increase the elongation at break of the fibers. Testing their hygroscopic parameters, a slight decrease of water retention in the modified fibers was observed, though such minor changes do not allow for the formulation of definite conclusions. A minor influence of nanosilica on the hygroscopic parameters of the obtained fibers was noticed. Therefore, it cannot be argued that modifiers influence the hydrophilic properties of modified cellulose fibers significantly.

Consequently, antibacterial cellulose fibers with silver nanoparticles and nanosilica obtained in this way are safe for humans and the environment, which means that they are appropriate for medical applications.

Acknowledgments This research was funded by the Ministry of Science and Higher Education in 2010-2013 as research project No. N N507615138.

Open Access This article is distributed under the terms of the Creative Commons Attribution 4.0 International License (http:// creativecommons.org/licenses/by/4.0/), which permits unrestricted use, distribution, and reproduction in any medium, provided you give appropriate credit to the original author(s) and the source, provide a link to the Creative Commons license, and indicate if changes were made.

\section{References}

Besinis A, Peralta T, Handy RD (2014) The antibacterial effects of silver, titanium dioxide and silica dioxide nanoparticles compared to the dental disinfectant chlorhexidine on Streptococcus mutans using a suite of bioassays. Nanotoxicology 8(1):1-16

Carbone M, Donia DT, Sabbatella G, Antiochia R (2016) Silver nanoparticles in polymeric matrices for fresh food packaging. J King Saud Univ Sci 28:273-279

Fede C, Selvestrel F, Compagnin C, Mognato M, Mancin F, Reddi E, Celotti L (2012) The toxicity outcome of silica nanoparticles (Ludox ${ }^{\circledR}$ ) is influenced by testing techniques and treatment modalities. Anal Bioanal Chem 404:1789-1802

Gokarneshan N, Velumani K (2017) Application of nano silver particles on textile materials for improvement of antibacterial finishes. Glob J Pharmaceut Sci 2(3):555586

Gutarowska B, Dymel M, Wieckowska-Szakiel M, Ciechanska D (2009) Metody ilosciowe oceny aktywnosci przeciwdrobnoustrojowej wyrobow wlokienniczych. Przeglad wlokienniczy WOS 3:34-37

He Q, Wu Z, Huang C, Zeng X (2012) Preparation and characterization of silver loaded antibacterial nanosilica particles. Adv Sci Lett 10:177-181

Kim IY, Joachim E, Choi H, Kim K (2015) Toxicity of silica nanoparticles depends on size, dose and cell type. Nanomed Nanotechnol Biol Med 11:1407-1416

Kozlowski R, Laszkiewicz B, Kulpinski P, Muzyczek M, Czarnecki P, Rubacha M, Niekraszewicz B, Jedrzejczak J, Peczek B (2009) Method of manufacturing silver nanoparticles, cellulosic fibers and nanofibers containing silver nanoparticles, fibers and nanofibers containig silver nanoparticles, use of silver nanoparticles to the manufacture of cellulosic fibers and nanofibers, and wound dressing containing silver nanoparticles. EP 2126146

Kulpinski P (2005) Cellulose fibers modified by silicon dioxide nanoparticles. J Appl Polym Sci 98:1793-1798

Kulpinski P (2007a) Cellulose fibers modified by hydrophobic type polymer. J Appl Polym Sci 104:398-409

Kulpinski P (2007b) Bioactive cellulose fibers with silver nanoparticles. E-polymers, no. 068

Kulpinski P, Laszkiewicz B, Niekraszewicz B, Czarnecki P, Rubacha M, Peczek B, Jedrzejczak J, Kozlowski R, Mankowski J (2005) The method of making modified cellulose fibers. EP 1601824

Laszkiewicz B, Czarnecki P, Kulpinski P, Niekraszewicz B, Rubacha M (2006) New generations of Lyocell fibers. Chem Fibers Int 4:234

Madhumati K, Sudheesh Kumar PT, Kevya KC, Furuike T, Tamura H, Nair SV, Jayakumar R (2009) Novel chitin/nanosillica composite scaffolds for bone tissue engineering applications. Int J Biol Macromol 45:289-292

Niekraszewicz (2006) Przemysl Chemiczny, 85/8-9, 959-961

Rabolli V, Thomassen LCJ, Uwambayinema F, Martens JA (2011) The cytotoxic activity of amorphous silica nanoparticles is mainly influenced by surface area and not by aggregation. Toxicol Lett 206:197-203

Schneider G (2017) Antimicrobial silver nanoparticles-regulatory situation in the European Union. Mater Today Proc 4:200-207

Smiechowicz E, Kulpinski P, Niekraszewicz B, Bacciarelli A (2011) Cellulose fibers modified with silver nanoparticles. Cellulose 18:975-985 
Smiechowicz E, Kulpinski P, Bemska J, Morgiel J (2014) Effect of silver nanoparticles shape, size and distribution on cellulose fibers' color. Color Technol 130:424-431

Srinivas K (2016) The current role of nanomaterials in cosmetics. J Chem Pharm Res 8(5):906-914

Sujoy KD, Khan MR, Parandhaman T, Laffir F, Guha AK, Sekaran G, Mandal AB (2013) Nano-silica fabricated with silver nanoparticles: antifouling adsorbent for efficient dye removal, effective water disinfection and biofouling control. Nanoscale 5:5549-5560

Wendler F, Meister F, Montigny R, Wagner M (2007) A new antimicrobial ALCERU fiber with silver nanoparticles. Fibers Text East Eur 15:41-45
Yu DG, Teng MY, Chou WL, Yang MC (2003) Characterization and inhibitory effect of antibacterial PAN-based hollow fiber loaded with silver nitrate. J Membr Sci 225:115-123

Zhang XF, Liu ZG, Shen W, Gurunathan S (2016) Silver nanoparticles: synthesis, characterization, properties, applications and therapeutic approaches. Int J Mol Sci 17:1534-1568

Zikeli S (2002) Sea Cell ${ }^{\circledR}$ Active-a new cellulosic fiber with antimicrobial properties. In: Conference proceedings Avantex-international forum and symposium for hightech apparel textiles, Frankfurt/Main, 13-15 March 2002 